\title{
Association between Deletion Polymorphism of the Angiotensin-Converting Enzyme Gene and Cerebral Atherosclerosis
}

\author{
Jadranka Sertić1 ${ }^{1}$, Danijela Hebrang ${ }^{2}$, Drago Januš $^{3}$, Branka Salzer $^{1}$, Martina Nikšić ${ }^{1}$, Dubravka Čvorišćec ${ }^{1}$ \\ and Ana Stavljenić-Rukavina ${ }^{1}$ \\ I Clinical Institute of Laboratory Diagnosis, Zagreb University Hospital, Zagreb, Croatia \\ 2 Institute of Clinical Chemistry, Merkur Clinical Hospital, Zagreb, Croatia \\ 3 Institute of Radiology, Merkur Clinical Hospital, Zagreb, Croatia
}

Summary: We investigated deletion polymorphism in the gene for angiotensin-converting enzyme in patients with angiographically verified cerebral atherosclerosis. Genotypes were determined by the polymerase chain reaction with oligonucleotide flanking of the polymorphic region of intron 16 of the angiotensin-converting enzyme gene.

Results of angiotensin-converting enzyme genotyping showed $46 \%$ of 50 studied patients to be homozygous for the DD allele, whose prevalence was significantly increased as compared with a group of controls without atherosclerotic changes. In this control group, the following genotypes were observed (\%): II $=24$, ID $=52$ and $\mathrm{DD}=24$. The frequency of the I and $\mathrm{D}$ alleles in the group of patients with cerebral atherosclerosis was 0.28 and 0.72 , respectively, whereas in the group without atherosclerosis it was 0.50 for both. Furthermore, in the present study, the DD genotype was associated with a high level of serum angiotensin-converting enzyme activity, total and LDL-cholesterol and triacylglycerol. A newly established association between DD genotype and cerebral atherosclerosis, detected even in our small group, supports the view that angiotensin-converting enzyme polymorphism might be indicative of the development of cerebral atherosclerosis.

\section{Introduction}

Cerebrovascular insufficiency is a multifactorial disease, influenced by risk factors such as disturbance of the lipid profile, gene polymorphism and blood pressure (1).

The renin-angiotensin system plays a major role in haemodynamic and fluid balance homeostasis. Renin ${ }^{1}$ ), a proteolytic enzyme, acts on angiotensinogen to generate the inactive prohormone angiotensin I. Angiotensinconverting enzyme ${ }^{1}$ ), a dipeptidyl carboxypeptidase, converts angiotensin I to a vasoconstrictor octapeptide, angiotensin II. Angiotensin-converting enzyme is responsible for the degradation of vasodilator kinins such as bradykinin.

Angiotensin-converting enzyme is mainly located on the endothelium of blood vessels, but it is also found in epithelial cells, blood mononuclear cells and macrophages (2). In recent years, there has been a renewed interest in the role of angiotensin II in smooth muscle cell proliferation, since data have been reported, suggesting that the inhibition of formation of angiotensin

\footnotetext{
1 Enzymes:

Renin= EC 3.4.23.15

Angiotensin-converting enzyme: Peptidyl-dipeptidase A, EC 3.4.15:1
}

II by angiotensin-converting enzyme inhibitors suppresses arterial lesion growth (3). In addition, several studies have assessed the effect of angiotensin-converting enzyme inhibitors. Administration of an angiotensin-converting enzyme inhibitor can decrease the formations of angiotensin II and the breakdown of bradykinin, thus reducing the risk of recurrent disease (4, $5)$. The angiotensin-converting enzyme gene has been cloned, and the gene effect shown to be associated with an insertion (I)/deletion (D) polymorphism of an Alu repeat in intron 16 of the angiotensin-converting enzyme gene. The I allele of the angiotensin-converting enzyme gene carries an intronic insertion not present in the D allele (6-8). Recent studies have shown angiotensin-converting enzyme polymorphism in the angiotensin I converting enzyme gene to be closely associated with some diseases. Zee et al. have determined the genotypes in patients with essential hypertension (9). Cambien et al. have suggested that a deletion polymorphism in the gene encoding angiotensin converting enzyme might be a risk factor for myocardial infarction, particularly in patients ordinarily considered at low risk for cardiovascular disease (10). The renin-angiotensin system and angiotensin-converting enzyme polymorphism have been shown to be associated with patients with ischaemic or idiopathic dilated cardiomyopathy $(11,12)$. 
To our knowledge, no investigation of angiotensin-converting enzyme I/D polymorphism in patients with cerebral atherosclerosis has been published to date. The present study was undertaken to investigate the possible relationship between homozygosity of the deletion allele and cerebral atherosclerosis.

\section{Materials and Methods}

The subjects were patients grouped for determination of biochemical risk factors for atherosclerosis, as well as angiography of the aortic arch and arteries proceeding to the brain; they were selected for suspected cerebrovascular insufficiency due to atherosclerotic changes in major cerebral arteries. Before they were sent for the final clinical diagnostic examination, all patients were tentatively diagnosed as having cerebrovascular insufficiency. The laboratory and angiographic examination applied in this investigation is used in the routine examination of patients affected by cerebral ischaemia, with the purpose of determining and grading atherosclerotic changes in cerebral arteries, and establishing a therapy plan.

A total of 75 subjects, 40 males and 35 females, aged $28-76$ years, were included in the study. On the basis of angiography of the cerebral arteries, they were divided into a group with atherosclerosis of the cerebral. arteries and a control group.

The control group comprised 25 patients of both sexes with angiographically excluded atherosclerotic changes in cerebral and peripheral arteries. Angiography was performed because cerebrovascular insufficiency was suggested by certain symptoms, and by the blood flow in the cerebral arteries determined by ultrasonography or radioactive isotopes (angioscintigraphy). Since angiography showed the cerebral arteries to be normal, the results from the blood flow determination of the cerebral arteries were falsely positive, and it was concluded that the symptoms were not caused by atherosclerosis of the cerebral arteries.

Analyses included clinical data on sex, age, lipid and lipoprotein level, angiotensin-converting enzyme-typing and systolic and diastolic blood pressure. In both groups, the medical history, the clinical survey and the electrocardiogram analysis offered no evidence of the presence of coronary heart disease. Blood pressure was measured by the standard cuff technique at rest.

\section{Angiotensin-converting enzyme genotype analysis}

Molecular analysis of the angiotensin-converting enzyme genotype of patients with cerebral atherosclerosis was performed by selective amplification of the polymorphic region in intron 16 of the angiotensin-converting enzyme gene (Alu repetitive sequence) by the polymerase chain reaction and gel electrophoresis.

Blood was taken with EDTA as anticoagulant. Erythrocytes were lysed and the pellet of nuclear leukocytes was used for isolation of DNA. Proteinase K was then added to the leukocytes, and the phenol-chloroform extraction of nucleic acids and precipitation with ethanol were performed. In vitro enzymatic amplification of DNA was carried out by mixing $1 \mu \mathrm{g}$ of genomic DNA, $10 \mathrm{pmol}$ of primers (5-CTGGAGACCACTCCCATCCTTTCT-3 and 5-ATGTGGCCATCACATTCGTCAGAT-3) in a final volume of $50 \mu \mathrm{l}$, containing $3 \mathrm{mmol} / \mathrm{l} \mathrm{MgCl}, 50 \mathrm{mmol} / 1 \mathrm{KCl}, 10 \mathrm{mmol} / \mathrm{l}$ Tris$\mathrm{HCl} \mathrm{pH} 8.4,0.1 \mathrm{~g} / \mathrm{l}$ gelatin, $0.5 \mathrm{mmol} / 1 \mathrm{dNTP}$ (Boehringer-Mannheim) and $1.25 \mathrm{U} \mathrm{Taq}$ polymerase (13). DNA was amplified for 35 reaction cycles, each cycle consisting of denaturation $1 \mathrm{~min}$ at $94^{\circ} \mathrm{C}$, primer annealing $1 \mathrm{~min}$ at $58^{\circ} \mathrm{C}$ and polymerisation $2 \mathrm{~min}$ at $72^{\circ} \mathrm{C}$ using a Thermocycler (B. Braun-biomed) (14). DNA amplification was followed by the analysis of the PCR product by submarine gel electrophoresis. An amount of $10 \mu \mathrm{l}$ was applied to a $20 \mathrm{~g} / \mathrm{l}$ agarose gel and submitted to electrophoresis for $2 \mathrm{~h}$ at $75 \mathrm{~V}$. The gel was then stained with ethidium bromide, illuminated with short-wave ultraviolet light, and photographed.
The reaction product was a 490 base pair fragment in the presence and a 190 base pair fragment in the absence of insertion.

\section{Serum angiotensin-converting enzyme measurement}

Serum angiotensin-converting enzyme activity was measured by a photometric method based on the quantification of hippuric acid from the substrate hippuryl-histidyl-leucine (15).

\section{Lipid and lipoprotein analysis}

Biochemical risk factors included the determination of plasma cholesterol, triacylglycerols, HDL-cholesterol and LDL-cholesterol. Plasma total and high density lipoprotein ( $\mathrm{HDL}$ ) cholesterol and triacylglycerols were measured enzymatically using commercial test kits (Boehringer-Mannheim) on an Abbott Spectrum analyser. HDL-cholesterol was determined after selective precipitation of LDL and VLDL with polyethylene glycol (16). Data were compiled according to genotype, and allele frequencies were calculated. Differences between the groups were analysed by the Mann \& Whitney method. A value of $\mathrm{p}<0.05$ was considered significant.

\section{Results}

Results of the angiotensin-converting enzyme genotype analysis are shown in figure 1. Homozygotes had a fragment of 490 base pairs if the repeat was present or 190 base pairs if the repeat was not present. Heterozygotes showed both fragments. Genotype frequencies according to the presence or absence of the repeat are compared with those of the controls in table 1. Distribution of $\mathrm{DD}$, ID and II genotypes in the patient group was $46 \%, 52 \%$ and $2 \%$, respectively. In the control group the following genotypes were observed: II in $24 \%$, ID in $52 \%$ and DD in $24 \%$. There was an excess of DD genotype and D allele frequency in patients with brain artery atherosclerosis, as compared with controls.

Patients with DD genotype had higher total cholesterol (tab. 2) and LDL-cholesterol, whereas the ID genotype was associated with elevated triacylglycerol, LDL and blood pressure, 'as compared with the control group.

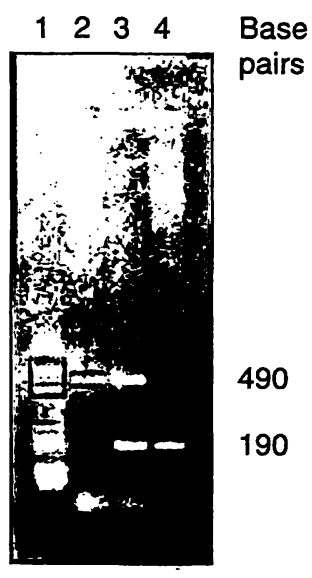

Fig. 1 PCR detection of the insertion/deletion polymorphism in intron 16 of the angiotensin-converting enzyme gene.

Lane 1 molecular mass markers

Lane 2 II homozygous (490 base pairs)

Lane 3 heterozygous $(490,190$ base pairs) :

Lane 4 DD homozygous (190 base pairs) 
Tab. 1 Distribution of angiotensin-converting enzyme genotypes and allele frequencies in 50 patients with angiographically estimated atherosclerotic disease of cerebral arteries, and in control subjects $(n=25)$.

\begin{tabular}{lcl}
\hline & Patients & Control subjects \\
\hline Angiotensin-converting enzyme genotype & $\cdot$ \\
DD & 46 & 24 \\
ID & 52 & 52 \\
II & 2 & 24 \\
Allelic frequency & & \\
I & 0.28 & 0.50 \\
D & 0.72 & 0.50 \\
\hline
\end{tabular}

The mean levels of the plasma angiotensin-converting enzyme catalytic concentration were 39.2 and $24.7 \mathrm{U} / 1$ for DD homozygotes and ID heterozygotes, respectively, as shown in table 2 . The highest angiotensin-converting enzyme activity was found in patients with the DD genotype, while only one patient with II genotype had a high level of angiotensin-converting enzyme activity.

\section{Discussion}

The present study compares the angiotensin-converting enzyme $I / D$ gene polymorphism, plasma angiotensinconverting enzyme catalytic concentration and lipid values in patients with angiographically confirmed atherosclerosis of cerebral arteries. The data obtained in the study show that $46 \%$ of patients with cerebral atherosclerosis were homozygous for the DD allele, indicating an increased prevalence of DD allele as compared with the control group. Furthermore, the ID genotype was found to be the most frequent (52\%), and the resulting frequencies of $D$ alleles were two and a half fold those of the I allele. In contrast, both the I and the D allele in the control group showed a frequency of 0.50 .

The study confirms the association between the plasma angiotensin-converting enzyme catalytic concentration and genetic polymorphism. The angiotensin-converting enzyme/DD genotype was associated with the highest plasma angiotensin-converting enzyme catalytic concentration in the patient group.

As expected, the mean value for total and LDL-cholesterol in all three genotypes was higher in patients than in controls, though the mean value for triacylglycerols was higher in the DD genotype only.

This latter observation points to a significant association of triacylglycerol with the DD genotype, but further research into its cause is necessary.

Zingone et al. have suggested that homozygosity for deletion of the angiotensin-converting enzyme gene might also be involved in the development of insulin resistance

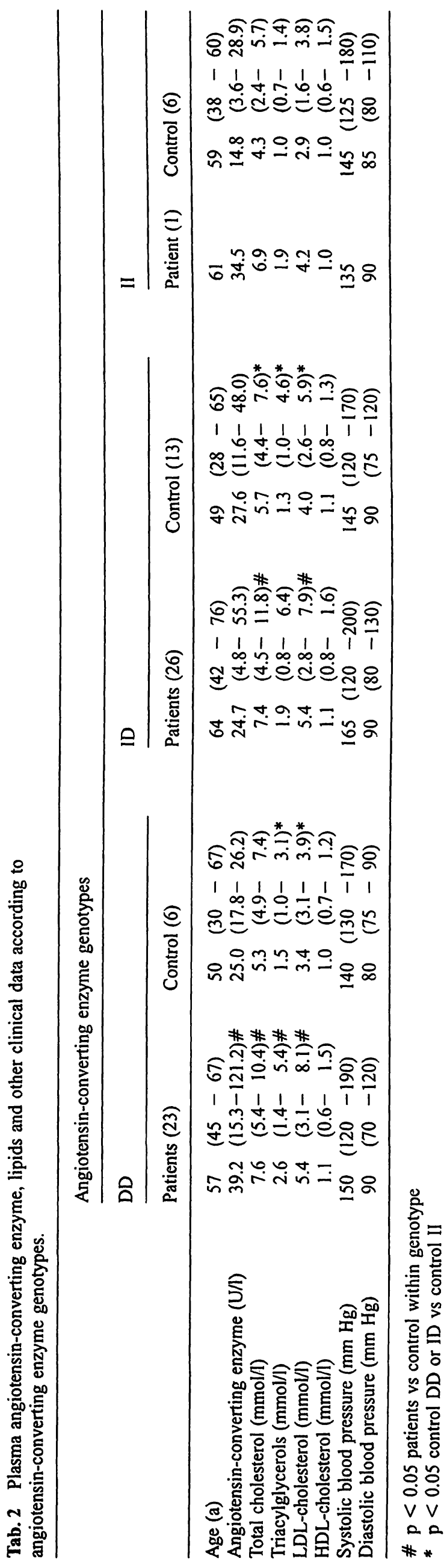


and even play a role in pathogenesis of hypertension and atherosclerosis in type II diabetes (17).

All patients which might have shown changes in the concentration of biochemical risk factors for atherosclerosis, but for other reasons, were excluded from our study, i.e. patients with liver disease, diabetes mellitus and diseases of the thyroid and other endocrine glands.

Results further indicated elevated blood pressure in the DD genotypes in the patient group. However, the evidence for the association of angiotensin-converting enzyme insertion/deletion polymorphism and atherosclerosis is not consistent. Several studies on the relationship between angiotensin-converting enzyme genotype and artery disease have been performed, but the results appear to be conflicting. In a recent study, Cambien found a close relationship between angiotensin-converting en-

\section{References}

1. Warden A, Thompson E. Apolipoprotein E and the development of atherosclerosis. Lab Med 1993; 25:449-55.

2. Erdös E, Skidgel RA. The angiotensin I-converting enzyme. Lab Invest 1987; 56:345-8.

3. Mercator Study group: Does the new angiotensin converting enzyme inhibitor Cilazapril prevent restenosis after percutaneous transluminal coronary angioplasty? Circulation 1992; 86:100-10.

4. Kurtz WT. The ACE of hearts. Nature 1992; 359:588-9.

5. Ferrario CM. The renin-angiotensin system: importance in physiology and pathology. J Cardiovasc Pharmacol 1990; 15 (Suppl 3):S1-S5.

6. Tiret L, Rigat B, Visvikis S, Breda C, Corvol P, Cambien F, et al. Evidence, from combined segregation and linkage analysis, that a variant of the angiotensin I-converting enzyme (ACE) gene controls plasma ACE levels. Am J Hum Genet 1992; 51:197-205.

7. Jacob $H$, Lindpaintner $K$, Lincoln $S$, Kusumi $K$, Bunker $R$, Mao Y, et al. Genetic mapping of a gene causing hypertension in the stroke-prone spontaneously hypertensive rat. Cell 1991; 67:213-24.

8. Paul M, Wagner J, Dzau V. Gene expression of the renin-angiotensin system in human tissues. J Clin Invest 1993; 91:2058-64.

9. Zee R, Lou Y, Griffiths L, Morris B. Association of a polymorphism of the angiotensin I-converting enzyme gene with essential hypertension. Biochem Biophys Res Commun 1992; 184:9-15.

10. Cambien F, Poirier O, Lecerf L, Evans A, Cambou J. Deletion polymorphism in the gene for angiotensin-converting enzyme is a potent risk factor for myocardial infarction. Nature 1992; 359:641-4.

11. Schunkert H, Hense H, Holmer S, Stender M, Perz S, Keil $U$, et al. Association between a deletion polymorphism of the angiotensin-converting-enzyme gene and left ventricular hypertrophy. N Engl J Med 1994; 33:1634-8. zyme deletion polymorphism and the risk of myocardial infarction in individuals considered at low risk according to certain other factors (18). Zee et al. (1992) found no significant differences in the distribution of the angiotensin-converting enzyme allele frequency between patients with èssential hypertension and control subjects (9). Lindpaintner et al. reported that the angiotensinconverting enzyme genotype could not be associated with ischaemic heart disease or myocardial infarction (19). The major finding of the present study, i. e. the high frequency of the $D$ allele in cerebrovascular atherosclerosis, is consistent with the findings of angiotensinconverting enzyme genetic polymorphism in cardiovascular atherosclerosis described by Cambien et al. This finding points to a general significance of the angiotensin-converting enzyme DD genotype as a potential risk predictor for atherosclerosis in general.

12. Raynold M, Bristow M, Buch E, Abraham W, Lowes B, Zisman $\mathrm{L}$, et al. Angiotensin-converting enzyme DD genotype in patients with ischaemic or idiopathic dilated cardiomyopathy. Lancet 1993; 342:1073-5.

13. Mulis KF, Fallona T. Specific synthesis of DNA in vitro via a polymerase-catalyzed chain reaction. Methods Enzymol 1987; 155:335.

14. Stavljenić-Rukavina A, Sertić J, Salzer B, Dumić M, Radica A, Fumić $\mathrm{K}$, et al. Apolipoprotein $\mathrm{E}$ phenotypes and genotypes as determined by polymerase chain reaction using allele-specific oligonucleotide probes and the amplification mutation system in children with insulin-dependent diabetes mellitus. Clin Chem Acta 1993; 216:191-8.

15. Cushman DW, Cheung HS. Concentration of angiotensin-converting enzyme in tissues of the rat. Biochim Biophys Acta $1971 ; 250: 261-5$.

16. Salzer B, Stavljenić A, Jurgens G, Dumić M, Radica A. Polymorphism of apolipoprotein E, lipoprotein (a), and other lipoproteins in children with type I diabetes. Clin Chem 1993; 39:1427-32.

17. Zingone A, Dominijanni A, Mele E, Marasco O, Melina F. Deletion polymorphism in the gene for angiotensin converting enzyme is associated with elevated fasting blood glucose levels. Hum Genet 1994; 94:207-9.

18. Cambien $F$. The angiotensin-converting enzyme (ACE) genetic polymorphism: its relationship with plasma ACE level and myocardial infarction. Clin Genet 1994; 46:94-101.

19. Lindpaintner K, Pfeffer M, Kreutz R, Stampfer M, Grodstein F. A prospective evaluation of an angiotensin-converting enzyme gene polymorphism and the risk of ischemic heart disease. N Engl J Med 1995; 332:11:706-11.

\section{Received August 14, 1995/January 3, 1996}

Corresponding author: Professor Ana Stavljenić-Rukavina, PhD, Clinical Institute of Laboratory Diagnosis, Zagreb University Hospital, Kišpatićeva 12, HR-10000 Zagreb, Croatia 